\title{
EURICO BRANCO RIBEIRO: DAS PRIMEIRAS LETRAS EM GUARAPUAVA À FORMAÇÃO EM MEDICINA NA CAPITAL PAULISTA
}

\author{
Claudia Rejane Schavarinski Almeida Santos ${ }^{1}$
}

\begin{abstract}
Resumo: O objetivo deste artigo é evidenciar a rede de sociabilidade familiar que envolve a trajetória educacional do médico paranaense Eurico Branco Ribeiro (1902 - 1978). Embora a pretensão dessa pesquisa não seja fazer uma biografia histórica, trataremos Eurico Branco Ribeiro na perspectiva de personagem histórica, um homem social, historicamente concreto, pois, desta forma, será possível percebê-lo de forma não linear, mas em movimento, dentro do contexto das suas ações e relações. Os pormenores significativos da trajetória de Eurico Branco Ribeiro evidenciam que sua formação na Faculdade de Medicina de São Paulo, foi o resultado de uma cadeia de relações, de capitais sociais e familiares que constituiu, assim, a base para sua grande visibilidade social que se estendeu para além do campo médico.
\end{abstract}

Palavras-chaves: Eurico Branco Ribeiro; trajetória educacional; biografia.

\section{EURICO BRANCO RIBEIRO: FROM THE FIRSTS LETTERS IN GUARAPUAVA TO THE MEDICAL FORMATION IN SÃO PAULO CAPITAL}

\begin{abstract}
This article intends to evidence the familiar social network that involves the educational trajectory of the physician from Paraná Eurico Branco Ribeiro (1902 - 1978). Although this research doesn't intend making a historical biography, we will conduce Eurico Branco Ribeiro by the historical personage, a social man, historically strong, because, thus, it will be possible perceive him in a non-linear way, but moving, within of his actions and relations contexts. The important details of Eurico Branco Ribeiro's trajectory evidence that his formation in São Paulo Medical School was the result of relations network, of his social and familiar capital, thus, the base for his great social visibility, which was known to beyond the medical context.
\end{abstract}

Key words: Eurico Branco Ribeiro; educational trajectory; biography.

- Enviado em 15/07/2017

- Aprovado em 28/07/2017

1 Mestranda do Programa de Pós-graduação em Sociologia da UFPR. Endereço eletrônico: emaildaclaudia2005@yahoo.com.br 


\section{INTRODUÇÃO}

Nos seus 76 anos de vida, Eurico Branco Ribeiro, fundou a Sociedade dos Médicos da Beneficência Portuguesa, a Sociedade Médica São Lucas, a Sociedade Brasileira de Escritores Médicos (atual Sobrames) e a Associação Médico-Espírita, todas na capital paulista. Foi também presidente, da Academia de Medicina de São Paulo, da Seção Brasileira do Colégio Internacional de Cirurgiões e membro do Instituto Nacional de Geografia e da Academia Paulista de Letras/SP. Promoveu a criação do Museu Visconde de Guarapuava e da Biblioteca Ruiz de Montoya, em Guarapuava/PR. Fundou e dirigiu o Sanatório São Lucas (1939) na capital paulista, onde estagiaram médicos do Brasil e de vários países do mundo.

Criou a Fundação para o Progresso da Cirurgia e foi diretor e redator, por 45 anos, dos Anais Paulistas de Medicina e Cirurgia. Recebeu os seguintes títulos honoríficos: Comendador da Ordem do Mérito Médico do Governo Brasileiro, Cidadão Honorário de Curitiba, Prefeito Honorário de San Antonio, Texas (USA), Membro Honorário da União Mundial de Escritores Médicos, Patrono do Centro Médico de Ponta Grossa. Escritor voraz que em vida publicou mais de trinta obras. (VIDA ROTÁRIA, 1978, p. 28). (ANEXO A)

Dessa maneira, este trabalho insere-se pelo campo de estudo da biografia sociológica, haja vista que nos últimos anos, "os estudos biográficos deixaram os bastidores e passaram para o primeiro plano da historiografia internacional, inclusive a brasileira" (SCHMIDT, 2000, p. 50). Mesmo sendo uma das primeiras formas de história e de não ter sido abandonada, até meados do século XX o gênero biográfico era considerado "velhusco, convencional e ultrapassado", a biografia foi julgada ultrapassada, "mais propensa à apologia do que à análise, pouco preocupada com as estruturas socioeconômicas, políticas e culturais e focada apenas nos fatos (DEL PRIORE, 2009, p.7; SCHMIDT, 2000, p.49).

A partir da década de 1980, vemos ressurgir o interesse pelo gênero biográfico, o que pode ser observado em termos conceituais o fato de que "é cada vez maior o interesse dos leitores por um gênero de escritos - uma escrita de si - que abarca diários, correspondências, biografias e autobiografias, independentemente de serem memórias e entrevistas de vida" configurando-se assim como um novo espaço de investigação histórica, aquele do privado, dos homens comuns, sendo assim possível trazer a tona novos objetos, metodologias e fontes (GOMES, 2004, p.7). Ou como salienta Roger Chartier: 
[...] o objeto da história [...] não são mais, as estruturas e os mecanismos que regulam, fora de qualquer controle subjetivo, as relações sociais, e sim as racionalidades e as estratégias acionadas pelas comunidades, as parentelas, as famílias, os indivíduos. (CHARTIER, 1994, p.104)

Assim, o fazer biográfico atual busca restaurar a individualidade, tornando relevante e necessário conhecer a vida de outros sujeitos (SCHMIDT, 1996, p. 171). No entanto, é preciso ficar atento porque este retorno ou ressurgimento da biografia, não deve ser entendido como a retomada de um gênero velho, mas precisa estar imbuído de uma reformulação de suas bases teórico-metodológicas, que não despercebe a relação indivíduo-sociedade e desloca o eixo da escolha dos personagens enfocados que no molde tradicional privilegiava os grandes vultos.

Como esclarece Bourdieu:

Os acontecimentos biográficos definem-se antes como alocações e como deslocamentos no espaço social, isto é, mais precisamente, nos diferentes estados sucessivos da estrutura da distribuição dos diferentes tipos de capital que estão em jogo no campo considerado. [...] não podemos compreender uma trajetória (ou seja, o envelhecimento social que, ainda que inevitavelmente o acompanhe, é independente do envelhecimento biológico), a menos que tenhamos previamente construído os estados sucessivos do campo no qual ela se desenrolou; logo, o conjunto de relações objetivas que vincularam o agente considerado pelo menos em certo número de estados pertinentes do campo - ao conjunto dos outros agentes envolvidos no mesmo campo e que se defrontaram no mesmo espaço de possíveis. Essa construção prévia é também condição de qualquer avaliação rigorosa do que poderíamos chamar de superfície social, como descrição rigorosa da personalidade designada pelo nome próprio, em um momento dado do tempo, por uma individualidade biológica socialmente instituída, que age como um suporte de um conjunto de atributos e de atribuições que permitem sua intervenção como agente eficiente nos diferentes campos. (BOURDIEU, 2006, p. 190) 


\section{A FAMÍlIA BRANCO RIBEIRO: ENTRE SÃO PAULO E PARANÁ}

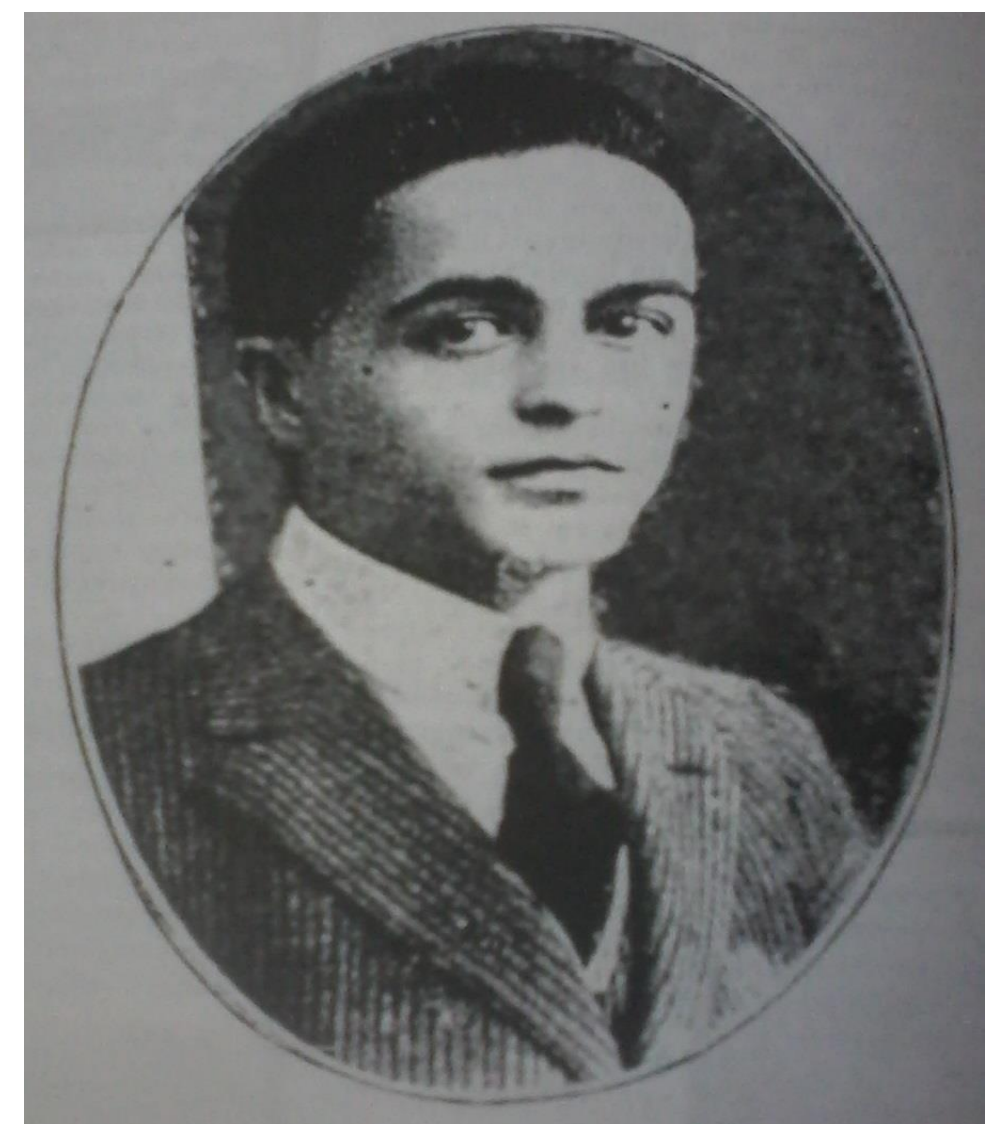

Fonte: Álbum de Guarapuava. 2 ed., 1928

Eurico Branco Ribeiro nasceu em 29 de março de 1902, em Guarapuava, no Estado do Paraná. Seus pais foram o paulista Arlindo Martins Ribeiro² e a guarapuavana Hermínia Saldanha Branco $^{3}$. Tendo sido alfabetizado e tido suas primeiras lições de educação formal na fazenda Trindade (pertencente à família), com a avó materna D. Alzira Saldanha Branco e com seu pai,

\footnotetext{
${ }^{2}$ Arlindo Ribeiro Martins nasceu em uma propriedade rural denominada Serrinha, em Iguape - São Paulo, em trinta e um de março de 1872, terceiro filho de Diogo Martins Ribeiro e Anna Rufina de Almeida Ribeiro que tiveram dezenove filhos. Com tenra idade, foi para o Rio de Janeiro e cursou a Escola Naval, mas após a Revolta da Armada, pede exclusão e passa a trabalhar como viajante de firma comercial de Manuel da Guia Ferreira, o que no decorrer de suas viagens o levou à cidade de Guarapuava, no Paraná, por volta de 1900, onde casou por duas vezes. Desligando-se da firma do Rio de Janeiro, associou-se a seu sogro na firma comercial que passa a se chamar Branco \& Arlindo e posteriormente com a dissolução da firma torna-se fazendeiro, passando a residir na Fazenda Trindade. Foi político atuante. Faleceu em Guarapuava em 30 de junho de 1937 (NICOLAS, 1954, p. 331; TEIXEIRA, L., 2000, p. 64; RIBEIRO, E. 1973, p. 4).
}

${ }^{3}$ Hermínia Saldanha Branco, filha mais nova do Coronel Eugenio Branco e de D. Alzira Saldanha Branco nasceu em Guarapuva, em 1882. Casou-se com Arlindo Martins Ribeiro em 17 de abril de 1901. Em 1904, dá a luz ao segundo filho, João Branco Ribeiro, filho este que falece dias depois, fatalidade que acometeu também D.Hermínia, três semanas após, ainda em decorrência das complicações do parto (TEIXEIRA, M., 2009, p.9; RIBEIRO, E. 1973, p. 4). 
Eurico Branco Ribeiro lembra: “[...] ela me ensinara a ler e a escrever, a reter as leis gramaticais e a ter noções da língua francesa. Ele lecionara aritmética, geografia e cosmografia. As aulas de história do Brasil foram com vovó; as de história Universal, com papai” (RIBEIRO, E. 1976, p.4). A mãe de Branco Ribeiro havia falecido quando ele tinha menos de dois anos. Em 1906, seu pai casou-se com a cunhada, Maria das Dores Branco, que também havia ficado viúva, com quem teve outros nove filhos.

As fazendas constituíam-se, no período em que Eurico Branco Ribeiro nasceu, em espaços importantes de convívio social na sociedade guarapuavana, sendo que os locais públicos no ambiente urbano eram utilizados essencialmente para encontros políticos e religiosos. O núcleo urbano guarapuavano, até por volta de 1960, “[...] apresentou um fraco dinamismo interno. Isso pode ser explicado pela dependência das atividades rurais como agricultura de subsistência e criação de gado" (SCHMIDT; LOBODA, 2011, p. 25), condição que tornava a prática educativa desenvolvida no âmbito familiar uma prática comum (TEMBIL, 2007).

Contudo, desde o início da República e principalmente no início do século XX, ganhou força a percepção da necessidade das crianças frequentarem a escola, como um sinal de modernidade que começava a despontar no país, pautado em grande parte no ideário positivista ${ }^{4}$. Essa condição, ainda incipiente nos municípios distantes das grandes cidades, era vinculada pela legislação. Nesse sentido, cabe ponderar que, se no Regulamento do Ensino de Instrução Pública do Estado do Paraná de 1901, artigo 22 fica reiterada a obrigatoriedade do ensino primário "para os meninos de sete a quatorze anos de idade, e para as meninas de sete a doze", como explicar o contexto que possibilitou que Eurico Branco Ribeiro obtivesse as primeiras letras em casa?

No caso de Eurico Branco Ribeiro, mesmo tendo sido alfabetizado no âmbito doméstico, Guarapuava já possuía uma estrutura educacional, ainda que incipiente, condição que merece uma análise mais abrangente, justificada pelo fato de Eurico ter citado em sua obra particularidades das escolas que existiam durante sua infância (RIBEIRO, E. 1942, p. 194).

Guarapuava, nas primeiras décadas subsequentes ao início de seu povoamento, em 1810, não dispunha de professores nomeados nem de escolas. Embora a Lei Geral da Instrução Pública,

\footnotetext{
${ }^{4}$ O ideário positivista, no Brasil, valorizava os aspectos culturais e pedagógicos, nos quais a educação era um componente considerado como relevante para propiciar a evolução da sociedade brasileira no início do século XX. A educação escolar era considerada como um veículo capaz de promover a concepção de ordem e progresso cultivada pelos dirigentes políticos e pelas elites do país, como também da então crescente burguesia. Mediante tais fatores, a escola passou a ser entendida como um mecanismo com condições de propagar o Positivismo na sociedade brasileira, resultando na efetivação de esforços para a "[...] massificação da escola, pleiteada pela burguesia, na construção do processo de hegemonia política e econômica dessa classe social na realidade brasileira" (OLIVEIRA, 2010, p. 15).
} 
de 15 de outubro de 1827 determinasse, em seu artigo $1^{\circ}$, a constituição de escolas de primeiras letras em todas as cidades, vilas e lugares mais populosos, Guarapuava terá que aguardar para que seja constituída sua primeira escola de primeiras letras.

No que diz respeito à educação formal, nas três primeiras décadas de sua constituição, os fazendeiros da região, que, apesar de possuírem residências na cidade, preferiam morar nas fazendas com a família e seus agregados, para poderem acompanhar de perto as atividades ligadas à agricultura e pecuária, contratavam instrutores, do sexo masculino, para ensinar os meninos a leitura, caligrafia, tabuada, as quatro operações aritméticas, geometria e sistema de pesos e medidas. Este instrutor ficava por um período em cada fazenda, onde os meninos se reuniam, transferindo-se em seguida para outra. Nas palavras de Marcondes:

Todos os exercícios eram feitos em lousas, devido a dificuldade de transporte e o preço dos cadernos. As famílias compravam uma cartilha e alguns livros de leitura que serviam para todos os filhos em idade escolar. [...] As meninas não aprendiam a ler. Recebiam os ensinamentos sobre trabalhos de agulha e prendas domésticas, pois a educação da mulher, naquele tempo, visava prepará-la para ser esposa e mãe, casta e submissa. (MARCONDES,1998, p. 140).

Embora haja convergências na literatura local, sobre quem foi a primeira professora de primeiras letras, pode-se apurar que foi por meio da lei $\mathrm{n}^{\circ} 23$ de 1842, que foi criada a cadeira de primeiras letras para a Freguesia de Nossa Senhora do Belém, que será ocupada pelo Sr. Severo Tristão Rodrigues, como aparece na ata da $3^{\text {a }}$ Sessão Ordinária de 26 de Janeiro de 1844, na Vila de Castro:

Severo Tristão Roiz mestre de primeiras letras da Freguezia de Goarapuava, remetendo a lista nominal de des alunos com alteração de dois que inda não existião ao tempo que remeteo a primeira, participando que continua a dar aulla na caza alugada pelo fiscal e que esta suprindo com todo os uthencilios necessarios the a decizão do Excelentíssimo Governo. (ATA da cidade de CASTRO, 1844 p. 1).

Inicialmente esta escola destinava-se somente a meninos, mas com o dispositivo da Lei $\mathrm{n}^{\mathrm{o}}$ 34 de 1846, da Província de São Paulo, passa a abrigar em seus bancos meninos e meninas. Em seu artigo oitavo a lei esclarecia que a frequência promíscua de ambos os sexos em uma escola, só era "permittida nos logares, onde não existam escolas diversas para ambos.” (SÃO PAULO, 1846, p.12).

Iniciava-se então o que se pode considerar o início formal do ensino das primeiras letras em Guarapuava. Primeiramente ele está atrelado aos dispositivos da Instrução Pública de São Paulo. Com a emancipação da Província do São Paulo, regulamentará seus próprios dispositivos de Instrução Pública da Província do Paraná. (PEREIRA, 1996, p.122). 
A formação educacional inicial, efetivada no âmbito doméstico, possibilitou a Eurico Branco Ribeiro, além da alfabetização e da assimilação dos primeiros conhecimentos científicos sistematizados, o interesse em obter uma formação educativa mais consistente, compatível com seu interesse em cursar medicina ${ }^{5}$. Houve, por sua parte, o reconhecimento do papel desempenhado pela avó materna na sua formação educacional, expondo que "[...] foi graças ao seu esforço pessoal que consegui mais tarde prosseguir nos estudos em que ela me iniciara” (RIBEIRO, E.,1942, p. 196).

Marcondes (1998) aponta que as instituições de ensino do final do século XIX e início do XX existentes na cidade de Guarapuava eram a Escola do Professor Yank (1873), o Instituto Becker (1902), o Colégio São José e o Colégio Nossa Senhora de Belém (1907), o Internato do Sr. Pedro Carli e o Grupo Escolar n. 4 (1910). Sendo assim, embora haja escolas públicas e particulares no município, a família de Eurico Branco Ribeiro valendo do dispositivo da lei, se encarregou de sua instrução primária.

A alfabetização de Branco Ribeiro no âmbito familiar repetia prática comum não somente em Guarapuava, mas na maioria das cidades de pequeno e médio porte existentes no Paraná e em todo o Brasil no início do século XX, incorporando-se a conduta educativa cultivada pelas famílias, em especial da elite, que possuíam um nível educativo com condições de desenvolver este processo educacional de maneira sistematizada. Vasconcelos (2005, p. 15), em relação a essa situação, assevera:

No Brasil, até o início do século XX, a educação doméstica era uma prática comum nas elites, constatada nos documentos pesquisados, não só para formação elementar, ou seja, para o ensino da leitura, escrita e contas, mas também para o ensino dos conhecimentos que eram considerados fundamentais à época e para a continuidade da formação de jovens, principalmente as meninas, que elaboravam ou aprimoravam sua educação na Casa. Os meninos, por sua vez, na maioria das vezes iniciavam sua educação no âmbito doméstico e, posteriormente, eram encaminhados para uma das instituições escolares existentes: particulares, religiosas ou oficiais, onde concluíam a formação secundária.

Os conhecimentos adquiridos por Eurico Branco Ribeiro no processo de alfabetização conduzido, com maior constância, por sua avó materna D. Alzira Saldanha Branco, envolveu, além do aprendizado da leitura e da escrita, a aprendizagem das normas gramaticais, noções da língua francesa, aritmética, geografia e cosmologia. Seu avô materno, Eugenio Branco, contribuiu com

\footnotetext{
5 Justificando a escolha da Medicina, como missão, Eurico Branco Ribeiro, cita uma passagem que lhe contaram quando criança e lhe acompanhou na vida adulta: "[...] quando se achava no leito de morte- eu ainda não tinha dois anos de idade - a minha mãe olhava para seu primogênito engatinhando e dizia-lhe confiante: - vai ser médico para curar sua mãezinha. Por isso ou por um pré- determinismo espiritual, o certo é que eu me fixei na idéia de estudar medicina [...]." (RIBEIRO, E., 1976, p. 3).
} 
aulas de História do Brasil e seu pai, Arlindo Martins Ribeiro, de História Universal. O conhecimento adquirido permitiu que Eurico Branco Ribeiro se tornasse, anos depois, um dos “[...] alunos mais adiantados do curso ginasial”. (RIBEIRO, E., 1976, p. 4).

Fragmentos de sua instrução primária são assim relembrados por Branco Ribeiro:

Quando eu era pequenino ... Não direi que a escola era risonha e franca. A ela fugiam os meus contemporâneos, porque ao invés de atrativos ela ainda apresentava, lá no sertão, onde eu nasci aquele aspecto contristador da palmatória a vista dos colegas, do castigo de joelhos sobre grãos de milho, dos puxões de orelha e das 500 linhas de cópia depois de terminadas as aulas. Eu não tive nada disso. E não tive talvez somente porque não freqüentava a escola. Aprendendo em casa, na fazenda, não senti nos primeiros tempos, a atração que pouco depois me jogou afoitamente, de corpo e alma, no castelo encantador dos livros de ensino. A lição era um pesadelo; quando se aproximava a hora de prestar contas da tarefa passada, na véspera, fugia para o fundo do quintal, onde não chegasse a voz de minha avó, ou saia a cavalo na ajuda aos campeiros, protelando por mais 24 horas o martírio do b-a-ba gaguejado, ou da taboada salteada. E quando me lembro do sacrifício enorme que me custou escrever com a mão direita - eu que tudo fazia com a esquerda - eu bendigo o esforço daquela que me orientou nos primeiros passos, porque tornando-me ambidestro, tenho obtido, com isso, extraordinárias vantagens na vida prática, principalmente dentro da minha atividade profissional [...]. (RIBEIRO, E., 1938, p. 194).

Em seus escritos Eurico Branco Ribeiro se refere sempre à figura de seu pai como incentivador de sua instrução formal e como exemplo de "temperança". À sua avó materna ele credita sua formação cultural e moral: "a minha avó devo [...] os elementos fundamentais para firmar normas de conduta pessoal de grande valia no enfrentar as contingências de um mundo revolto [...].”(RIBEIRO, E., 1976, p.5).

Importante destacar como, nas palavras do filho, era destacada a atuação de Arlindo Martins Ribeiro na administração pública:

A vida cívica de Arlindo iniciou-se na campanha presidencial de 1909. Seu sogro pertencia tradicionalmente ao partido maragato, que apoiava a candidatura do marechal Hermes da Fonseca. Mas Arlindo não tinha simpatias pelo militarismo e lançou-se em propaganda do civilismo, apoiando a canditadura de Ruy Barbosa. Essa atitude bem mostrou o seu temperamento independente, alheio a conveniências políticas. E, realmente, nunca foi um militante partidário. Calmo, ponderado, ouvia sempre os mais experientes, mas tomava as atitudes que o bom senso lhe indicava. (RIBEIRO, E., 1973, p. 7).

A inserção de Arlindo Martins Ribeiro nos meandros da vida pública, nas primeiras décadas do século XX, como vereador, deputado estadual e prefeito de Guarapuava por dois períodos ${ }^{6}$,

\footnotetext{
${ }^{6}$ Arlindo Martins Ribeiro tornou-se camarista em 1909. Em 1915 é convidado pela associação comercial de Curitiba para concorrer ao órgão legislativo do Estado, obtendo a mais alta votação da chapa (9.993 votos), ficando no exercício do cargo por dois anos, destacando-se em defender o acordo que deu término ás disputas do Contestado e em propor e defender a abertura de uma estrada entre Guarapuava e rio Paraná. Foi prefeito de Guarapuava duas vezes: de 1921 a 1922 e de 3 de março de 1932 a 1936, nomeado por Manuel Ribas, interventor do Estado (NICOLAS, 1954, p. 331;
} 
propiciará a Eurico Branco Ribeiro um acesso privilegiado a relatos de discussões, relatórios etc. Um corpus documental que norteará suas pesquisas acadêmico-científicas sobre o questões da saúde pública na localidade natal e região, pesquisas publicadas especialmente em duas obras, As águas Medicamentosas Naturaes (1927) e O Coração do Paraná (1929).

\section{OS ESTUDOS DE EURICO BRANCO RIBEIRO NA TERRA DOS BANDEIRANTES}

Depois de ser alfabetizado e receber uma educação primária em casa, com o pai e os avós, Eurico Branco Ribeiro foi enviado para casa de seus tios paternos, em São Paulo, para dar continuidade a seus estudos. A escolha da capital paulista como local da continuação da educação formal de Eurico Branco Ribeiro pode ser analisada pela questão geográfica pois essencialmente, a população que se instalou em Guarapuava era paulista, como esclarece Tembil "a conquista dos campos guarapuavanos deu-se por expedição originária dos domínios curitibanos, entretanto, esses domínios juridicamente, diziam respeito á Quinta Comarca de São Paulo, assim como seu povoamento deu-se majoritariamente por paulistas.” (TEMBIL, 2007, p. 64).

Sendo assim, praticamente todo o cenário que constituiu o povoado em seus primeiros anos lembrava a constituição das primeiras vilas paulistas. Outro aspecto que pode ser relacionado à escolha pela capital paulista é a posição geográfica de Guarapuava. Antiga rota de tropa, a localidade tinha ligação terrestre mais fácil com São Paulo do que com Curitiba.

O movimento das tropas que passavam em direção á Feira de Sorocaba, em São Paulo, imprimia um novo ritmo ao cotidiano da cidade na medida em que o contato dos guarapuavanos que passaram a integrar tais tropas com outros centros permitiu o acesso a vivência moderna. (TEMBIL, 2007, p.76).

Foi graças ao tropeirismo que este acesso a "vivência moderna" alterou o cotidiano da população, e a vida se sofisticou: os móveis, os produtos de higiene, a vestimenta, a arquitetura... Enfim, em busca do que se pode chamar de sintonia com a vida moderna, inegavelmente ocorrerá um estreitamento com grandes centros urbanos, notadamente São Paulo.

No entanto o que chama a atenção e onde se ancora esta pesquisa são as relações familiares da elite política-empresarial. O pai de Eurico, Arlindo Martins Ribeiro, possuía parentes em São Paulo, que puderam recebê-lo durante os anos que cursou o ginásio e depois a Faculdade de Medicina, como o próprio Branco Ribeiro nos relata:

TEIXEIRA, 2000, p. 64). Comentários de Branco Ribeiro sobre a atuação política do pai: RIBEIRO, E.,1942, p.196; 1973 , p. 8-13. 
Nos doze anos de estudo em São Paulo - seis de preparatórios no Ginásio N. S. do Carmo e no Ginásio do Estado e seis na Faculdade de Medicina mais tarde incorporada à Universidade de São Paulo - tive o apoio maternal de minha tia Anita, irmã de papai e esposa de Paulo Ayres, que também sempre me tratou como filho. O casal abrigou-me em seu lar por todo este grande período [...]. (RIBEIRO, E., 1976, p.6).

Este tio a quem Eurico, refere-se de maneira tão sentimental e com reverencia, tratava-se de um dos maiores empresários da indústria farmacêutica paulista. Paulo Ayres foi presidente do Instituto Pinheiros - Produtos Terapêuticos SA. (IP). Segundo Maria Alice Rosa Ribeiro (2001), tal instituição está ligada a um contexto de articulação da Saúde Pública com a indústria de larga escala, iniciado em fins do século XIX e início do século XX. Nele, a indústria farmacêutica brasileira torna-se exemplo da articulação entre ciência, medicina experimental e políticas de saúde pública, tanto no Rio de Janeiro como em São Paulo.

O início do Instituto Pinheiros, em 1928, está ligado à própria formação de pesquisadores em institutos públicos e o investimento de empresas nacionais em compostos biológicos, numa conjuntura favorável à modernização da indústria brasileira.

Já consolidado no mercado farmacêutico, a instituição receberia grande impulso na década seguinte. Em 1941, o Instituto Pinheiros recebeu grande aporte de capital dos novos sócios, Paulo Ayres e Paulo Ayres Filho, chegando a um valor de mercado de US\$162.162,16. Em seguida, em 1945, foi transformada em Sociedade Anônima, e na década de 1950 chegou a ter 1.200 funcionários, com 12 filiais pelo país. Segundo Ribeiro, uma das razões de seu sucesso foi o foco em produtos biológicos, com grande demanda no país, e um segmento em que grandes indústrias estrangeiras tinham participação insignificante e a produção estava baseada em instituições públicas. Nesta área, reuniu uma grande equipe de cientistas, alcançou excelência de produção de vacinas de introdução oral, e manteve um padrão tecnológico altamente elevado de controle de qualidade (RIBEIRO, M., 2001, p. 11).

Foi depois de fixar residência na capital paulista que Eurico Branco Ribeiro deu continuidade aos seus estudos. Entre 1916 e 1917, estudou no Grupo Escolar do Carmo ${ }^{7}$ entre 1918 a 1921 no Ginásio do Estado ${ }^{8}$.

\footnotetext{
${ }^{7}$ Foi conhecida durante muito tempo pela denominação de Escola Modelo do Carmo, ou Escola do Carmo. Essa escola foi fundada em 7 de julho de 1890 , e, em $1^{\circ}$ de setembro do mesmo ano, iniciou suas atividades. A escola passou a se chamar oficialmente Grupo Escolar do Carmo em $1^{\circ}$ de outubro de 1894. Sobre as escolas modelo confira SOUZA, 1998, p. 25-61.
} 
Neste fez parte do Grêmio Estudantil 16 de Setembro, que publicava a revista A Tesoura, na qual Branco Ribeiro desempenhou a função de redator no ano de 1921. Este periódico contemplava em suas páginas situações do cotidiano do Ginásio por meio de crônicas, caricaturas, seção de humor, entre outras.

Mais do que propiciar as gaiofagens de participar e redigir a revista humorística do Grêmio Estudantil, estes anos no Colégio do Estado propiciaram a Eurico Branco Ribeiro a ampliação nas discussões sobre como prosseguir os estudos, concorrendo para a definição pelo curso de medicina. Dos colegas de turma, um total de quarenta (trinta e oito alunos e duas alunas), seis seguiram a mesma profissão: Cincinato Pomponet Filho, Carlos Augusto Asbahr, Estevam José de Almeida Prado, Francisco Cerruti , João Alves Meira e Nelson de Souza Campos. Muito embora ao se referir em discursos sobre a escolha pela Medicina como um pedido de sua mãe no leito de morte, - "Você vai ser médico para curar sua mãezinha”. (RIBEIRO, E., 1976, p.1) - o estímulo recebido no ambiente escolar e as interlocuções com seus colegas podem ser considerados como fatores que fortaleceram este suposto desejo materno.

Juntamente com a continuidade de seus estudos, a capital paulista propiciará a Eurico Branco Ribeiro a ampliação de sua inserção no universo jornalístico iniciada nos jornais de Guarapuava:

Aos dez anos, Eurico Branco Ribeiro já escrevia para o jornal semanal "A Nação" de sua terra natal. Aos 12 anos, colaborava no "A Comarca de Guarapuava". Mudando-se para São Paulo, aos 13 anos, tornou-se redator da edição vespertina "O Estadinho" do jornal "O Estado de S. Paulo", tendo participado também do primeiro grupo de redatores da empresa "Folha da Noite", como repórter policial, advindo talvez daí sua enorme facilidade em descrever situações as mais inusitadas. (BEGLIOMINI, 2010, p.1).

A relação de Branco Ribeiro com o jornalismo foi duradoura como é possível constar em vários de seus textos, nos quais existem referências ao trabalho jornalístico. Um exemplo da atuação de Eurico Branco Ribeiro nessa área é o registro do Livro de Visitas da Santa Casa de Misericórdia de Itapira (cidade do estado de São Paulo), no qual o jovem Branco Ribeiro se credencia como representante do jornal paulistano Folha da Noite, para realizar a cobertura da visita do presidente de São Paulo, Washington Luís, àquela instituição em 4 de novembro de 1921. Segundo o próprio

\footnotetext{
${ }^{8}$ Trata-se do primeiro ginásio da cidade de São Paulo, instalado em 16 de setembro 1894. Uma instituição que se tornou referência no ensino secundário; durante várias décadas passaram pelas suas salas de aula futuros líderes políticos, empresários, intelectuais e cientistas (MONFREDINI, 2006, p.3).
} 
Eurico Branco Ribeiro, sua atuação na imprensa em geral continuou mesmo depois de formado em medicina:

[...] as lides da imprensa, que me fizeram conhecer de perto todos os setores da feitura de um jornal - desde a revisão tipográfica, a tradução de telegramas e a reportagem mais variada até a crônica, o comentário da redação e o artigo de fundo - tiveram continuidade na direção da revista "Anais Paulista de Medicina e Cirurgia" por mais de quarenta anos. Assim, fiquei ligado à imprensa e seus órgãos associativos mesmo depois de terminado o curso médico. (RIBEIRO, 1976, p.6).

Em diferentes escritos, Eurico Branco Ribeiro ressalta como sua inserção no jornalismo foi significativa para o custeio de seus estudos na capital paulista, primeiramente no curso ginasial, depois ao cursar os primeiros anos da Faculdade de Medicina e Cirurgia de São Paulo (RIBEIRO, E., 1971, p.18; 1976, p.6). Paralelamente, aparece nesses textos o empenho de sua família guarapuavana para mantê-lo estudando na cidade de São Paulo. Branco Ribeiro afirma que, para "suprir suas necessidades indispensáveis," sua avó empenhava-se no "fabrico de queijos" (RIBEIRO, 1976, p. 7). Essa lembrança difundida pelo médico, que assim concorria para a construção de uma memória sobre si mesmo (ARAUJO, 2010, p.120-148), de que se formou em medicina graças a "muito sacrifício", pode parecer contraditória se levarmos em conta que, como presente de formatura, recebeu de seu tio, "quantia" que lhe permitiu instalar consultório e fazer uma viagem a Argentina, participando de uma caravana médica brasileira (RIBEIRO, E., 1976, p.7). Entretanto, cabe também relembrar que o pai e avós maternos de Branco Ribeiro eram fazendeiros, o que neste período não significava necessariamente ter acúmulo de fortuna, mas sim posse de uma grande extensão de terras, provenientes das sesmarias, que era administrada austeramente. Já os tios que o abrigaram em sua casa dispunham de uma condição financeira confortável, pois como evidenciado, Paulo Ayres era um empresário de destaque da elite paulistana.

Mas, com "muito sacrifico" ou não, a admissão na Faculdade de Medicina e Cirurgia de São Paulo representou para Eurico Branco Ribeiro um período de importantes aprendizagens de ampliar sua rede de sociabilidade, que não se limitaram ao ofício da Medicina, mas também de desenvolvimento de uma percepção particularizada acerca da profissão e da sociedade.

Eurico Branco Ribeiro prestou exame de admissão e foi matriculado na Faculdade de Medicina e Cirurgia de São Paulo, em 14 de março de 1922, como discente da $10^{\mathrm{a}}$ turma de medicina. (ANEXO B). 
Começou então, seu envolvimento ativo no mecanismo dinâmico da Faculdade, não somente no que tange as atividades curriculares, mas dedicará grande parte de seu tempo à produção científico-acadêmica.

Sua produção refletirá sua articulação com as discussões sobre a saúde pública, que no Brasil ganha consistência impar a partir da proclamação da República, por meio de "um novo tipo de orientação técnica ditada principalmente pela medicina, que previa, com o saneamento físico do meio, a inclusão da higiene nas cidades, afastando o perigo das epidemias." (CAMPOS, 2002, introdução).

A Faculdade de Medicina e Cirurgia de São Paulo, na qual ingressou Ribeiro Branco, vincula-se a expansão do Ensino Superior no país na área de saúde. Esse processo pauta-se no fato de essa área "[...] expandir-se para novos campos de estudo, análise e atuação profissional" (CAMPOS, 2004, p. 159). Para a sociedade paulistana, a organização da Faculdade de Medicina e Cirurgia de São Paulo representou uma importante conquista. Passadas décadas da instalação das Faculdades de Medicina da Bahia e do Rio de Janeiro, São Paulo buscava o ingresso no universo do ensino médico acadêmico. Dominando a riqueza oriunda do café, a elite paulista buscava consolidar sua posição no cenário político nacional que, com o advento da República, favorecia projetos que pudessem dar destaque aos paulistas, em especial nas áreas de saúde e educação. Para isso, a ideia de uma faculdade de medicina, unindo educação e saúde, parecia ter terreno fértil para firmar-se e desenvolver-se.

Maria Alice Rosa Ribeiro (1993), ao tratar das transformações ocorridas em São Paulo, no século XIX, nos informa:

Na última década do século passado, ocorreu uma verdadeira epidemia de urbanização, [...] quando a cidade de são Paulo passou de 65 mil habitantes, em 1890, para 240 mil, em 1900. A fisionomia da cidade começou a mudar. A pacata cidade dos estudantes da Faculdade de Direito do Largo São Francisco transformava-se numa cidade comercial, financeira e industrial. (RIBEIRO, M.,1993, p. 101).

A constituição da grade curricular da $10^{\mathrm{a}}$ turma de Medicina (1924), da qual Eurico Branco Ribeiro fazia parte, ficou constituída de 30 disciplinas depois da reforma de 1926. Além das 26 cadeiras (previstas pelo decreto Federal $n^{\circ}$ 3.902, de 12 janeiro de 1901), a Faculdade paulista, em seu regulamento redigido em 7 de janeiro de 1913, já oferecia duas cadeiras não contempladas nas cláusulas federais: a clínica oftalmológica e a clínica otorrinolaringológica. A partir de 1916, mais 
duas cadeiras são incorporadas: higiene e patologia. Em 1918, com apoio da Fundação Rockefeller, é criado o Instituto de Higiene (MOTA, 2005, p.182).

Entre os professores de Branco Ribeiro estavam: Flamínio Fávero, de medicina legal e Domingos Rubião Meira, de clínica médica, que juntamente com Arnaldo Vieira de Carvalho foram protagonistas centrais na organização da Faculdade de Medicina e Cirurgia de São Paulo em 1912; Francisco Borges Vieira, que em 1924 assume a cadeira de higiene até então sob a responsabilidade de Geraldo Horácio de Paula Souza, e Benedicto Montenegro, de técnica cirúrgica e cirurgia experimental (LACAZ; MAZZIERI, 1995).

Em especial, Francisco Borges Vieira e Benedicto Montenegro desempenharam influências marcantes na formação médica de Eurico. O primeiro responsável pela inserção de Branco Ribeiro nas discussões acerca de questões sanitárias e na produção de escritos sobre a temática e o segundo pela escolha de sua especialização médica: a cirurgia geral com ênfase na gastrectomia.

Estes pormenores significativos da trajetória de Eurico Branco Ribeiro evidenciam que sua formação na Faculdade de Medicina de São Paulo, foi o resultado de uma cadeia de relações, de capitais sociais e familiares e constituiu assim a base para sua grande visibilidade social que se estendeu para além do campo médico, como expressou o diretor responsável pela revista Vida Rotarya:

[...] Era um erudito e um pensador - talvez um dos últimos representantes de uma fauna quase em extinção. Cada um dos seus livros contém um mundo de idéias. E, tão gulosamente as colhia e espalhava que elas escorriam de suas palestras fecundas, substanciosas e ricas, como o leite que a criança deixa vazar dos cantos da boca, depois de mamar, saciada e feliz. (VIDA ROTARYA, 1978, p.1). 


\section{FONTES}

ATA da Comarca de Castro.26 jan. 1844

RIBEIRO, E. B. $10^{\circ}$ aniversário da turma de 1927 da Faculdade de Medicina de São Paulo. São Paulo: São Paulo Editora Ltda., 1938.

RIBEIRO, E. B. Arlindo Martins Ribeiro: esboço biográfico. São Paulo: São Paulo Editora Ltda., 1973.

. À guisa de despedida: palavras proferidas perante a Legião médica São Lucas em Ponta Grossa, Paraná, em 16 de janeiro de 1976. São Paulo: Sangiard,1976.

Rotary para mim é .... São Paulo: Editora Anchieta Limitada, 1942.

Um grande mestre da cirurgia no Brasil: professor Emérito Benedicto Montenegro. São Paulo: São Paulo Editora Ltda., 1971.

VIDA ROTÁRIA. São Paulo: Fundação de Rotarianos de São Paulo, ano XXX, n 278, 1978. Edição especial.

\section{REFERÊNCIAS}

ARAUJO, S. A. C. de. Professora Julia Wanderley, uma mulher-mito (1874 -1918). 2010. 183

f. Dissertação. (Mestrado em Educação) Universidade Federal do Paraná, Curitiba, 2010.

BEGliomini, H. Eurico Branco Ribeiro. Academia Paulista de Medicina. Disponível em: <http://www.academiamedicinasaopaulo.org.br/images/academicos/114/12881986702010.pdf>. Acesso em: 12 jun. 2010.

BOURDIEU, P. A ilusão biográfica. In: AMADO, J.; FERREIRA, M. de M. (Org.). Usos e abusos da história oral. 8. ed. Rio de Janeiro: Editora FGV, 2006. p. 183-191.

CAMPOS, C. de. São Paulo pelas lentes da Higiene: as propostas de Geraldo Horácio de Paula Souza para a cidade (1925-1945). São Carlos: RiMa, 2002.

CAMPOS, C. de. A Fundação Rockefeller e o desenvolvimento da higiene enquanto disciplina e modelo de administração sanitária em São Paulo. Horizontes, Minas Gerias, v. 22, n. 2, p. 159-174, jul./dez. 2004.

CHARTIER, R. A História hoje: dúvidas, desafios e propostas. Estudos Históricos. Rio de Janeiro, n.13, v.7, p.97-113, 1994.

DEL PRIORE, Mary. Biografia: quando o indivíduo encontra a História. Topoi, v.10, n. 19, 2009, p. 7-16. Disponível em:<http://www.revistatopoi.org/numeros_anteriores/topoi19/topoi\%2019\%20\%2001\%20artigo\%201.pdf.> Acesso em: 24/02/2017.

GOMES, A. C. Escrita de si, escrita da História: a título de prólogo. In: GOMES, A. C.

(Org.). Escrita de si, escrita da história. Rio de Janeiro: Editora da FGV, 2004. 
LACAZ, C. da S. L.: MAZZIERI, B. R. de. A Faculdade de Medicina da USP. São Paulo: EDUSP, 1995.

MARCONDES, G. G. Guarapuava: história de luta e trabalho. Guarapuava: UNICENTRO, 1998

MONFREDINI, I. O regime de progressão continuada diante da cultura de uma escola “tradicional”. Reunião anual da Anped, 29., Caxambú. Anais...Caxambú, 2006.

MOTA, A. Tropeços da Medicina Bandeirante: medicina Paulista entre 1892- 1920. São Paulo: EDUSP, 2005.

NICOLAS, M. 130 Anos de Vida Parlamentar Paranaense: Assembléias Legislativas e Constituintes. 1854-1954. Curitiba: Assembléia Legislativa do Paraná, 1954.

OLIVEIRA, C. G. de. A matriz positivista na educação brasileira: uma análise das portas de entrada no período Republicano. Diálogos Acadêmicos: Revista Eletrônica da Faculdade

SEMAR/UNICASTELO, v. 1, n. 1, p. 1-17, jan. 2010.

PEREIRA, J. de S. M. Aspectos históricos do ensino primário no Brasil e, em especial, no estado do Paraná. 1996. 303f. Dissertação (Mestrado em História) Faculdade de Educação. Universidade Estadual de Campinas, Campinas, 1996.

RIBEIRO, M. A. R. História sem fim... inventário da saúde pública. São Paulo: UNESP, 1993. Saúde pública e as empresas químico-farmacêuticas. História, Ciência, SaúdeManguinhos, Rio de Janeiro,v.3,p. 607 - 626, nov. 2000 - fev.2001.

SÃO PAULO. Lei No 34 de 16 de março de 1846. Repertório das leis promulgadas pela Assembléia Legislativa da Província de São Paulo desde 1835 até 1857. Disponível em:

<http://www.usp.br/niephe/publicacoes/docs/ANEXOS.pdf.>. Acesso em: 10 set. 2016.

SCHMIDT, B. B. Luz e papel, realidade e imaginação: as biografias na História, no Jornalismo, na Literatura e no Cinema. In: O biográfico: perspectivas Interdisciplinares. Santa Cruz do Sul: EDUNISC, 2000, p. 49-70.

O gênero biográfico no campo do conhecimento histórico: trajetórias, tendências e impasses atuais e uma proposta de investigação.. Anos 90 (UFRGS. Impresso), Porto Alegre, v. 6, p. 165-192, 1996.

SCHMIDT, L. P.; LOBODA, C.R. A cidade enquanto um espaço desigual: o caso de Guarapuava PR. Caminhos da Geografia, Uberlândia, v. 12, n. 39, p. 21-30, set. 2011.

SOUZA, R. F. Templos de civilização: a implantação da Escola Primária Graduada no Estado de são Paulo (1890-1910). São Paulo: fundação Editora UNESP, 1998. 
TEIXEIRA, L. C. Terceiro Planalto. Guarapuava, 2000.

TEIXEIRA, M. W. Genealogia do Capitão Rocha. Guarapuava, 2009.

TEMBIL, M. Em busca da cidade moderna: Guarapuava... recompondo histórias, tecendo memórias. Guarapuava: UNICENTRO, 2007.

VASCONCELOS, Maria Celi Chaves. A casa e os seus mestres: A educação no Brasil de Oitocentos. Rio de Janeiro: Gryphus, 2005. 


\section{ANEXOS}

\section{Anexo A - Livros publicados por Eurico Branco Ribeiro}

\begin{tabular}{|c|c|}
\hline TÍTULO & ANO DA $1^{a}$ EDIÇÃO \\
\hline 1 - Esboço da História de Guarapuava & 1922 \\
\hline $2-\grave{A}$ Sombra dos Pinheiraes & 1925 \\
\hline 3 - Hygiene da imprensa. & 1926 \\
\hline 4-As Águas Medicamentosas Naturaes & 1927 \\
\hline 5 - Gralha Azul & 1927 \\
\hline 6- O Coração do Paraná & 1929 \\
\hline 7 - Sobre Mama Supranumerária & 1931 \\
\hline 8 - Estudos Cirúrgicos (6 volumes) & $1934 / 1952$ \\
\hline 9- A Caseose dos Nervos na Lepra & 1934 \\
\hline 10 - Pesquisa da Alça Jejunal em Cirurgia Gástrica & 1940 \\
\hline $11-$ Rotary para mim é... & 1942 \\
\hline 12 - Um lema para o Rotary & 1942 \\
\hline 13 - Litíase do Apêndice & 1943 \\
\hline 14 - Varicocele & 1946 \\
\hline $15-$ O Primeiro Bandeirante & 1946 \\
\hline 16 - A Penicilina por Via Arterial nas Osteomielites & 1947 \\
\hline 17 - Tópicos Rotarios & 1947 \\
\hline 18 - Rotary, o legado de Paul Harris & 1948 \\
\hline $19-$ Assim é o Rotary & 1952 \\
\hline 20 - O Rotary em evolução & 1954 \\
\hline 21 - O Rotary aos 50 anos & 1956 \\
\hline 22 - O Casamento Ideal & 1956 \\
\hline $23-25$ anos de Rotary & 1961 \\
\hline 24 - Pelas Avenidas do Rotary & 1961 \\
\hline $25-$ O Rotary Sexagenário & 1965 \\
\hline 26 - Atividades Internacionais do Rotary & 1965 \\
\hline 27 - A Água da Esperança & 1969 \\
\hline $28-$ O Primeiro Casamento & 1969 \\
\hline 29 - O Livro que Lucas não Escreveu & 1969 \\
\hline 30 - Médico, Pintor e Santo (3 volumes) & $1969 / 1970$ \\
\hline 31 - O Homem que marcou o Dia de Natal & 1972 \\
\hline 32 - Arlindo Martins Ribeiro: esboço biográfico & 1973 \\
\hline
\end{tabular}

Fonte: a autora (2017) 


\section{Anexo B - Comprovante de matrícula na Faculdade de medicina e Cirurgia de São Paulo} $(14 / 03 / 1922)$

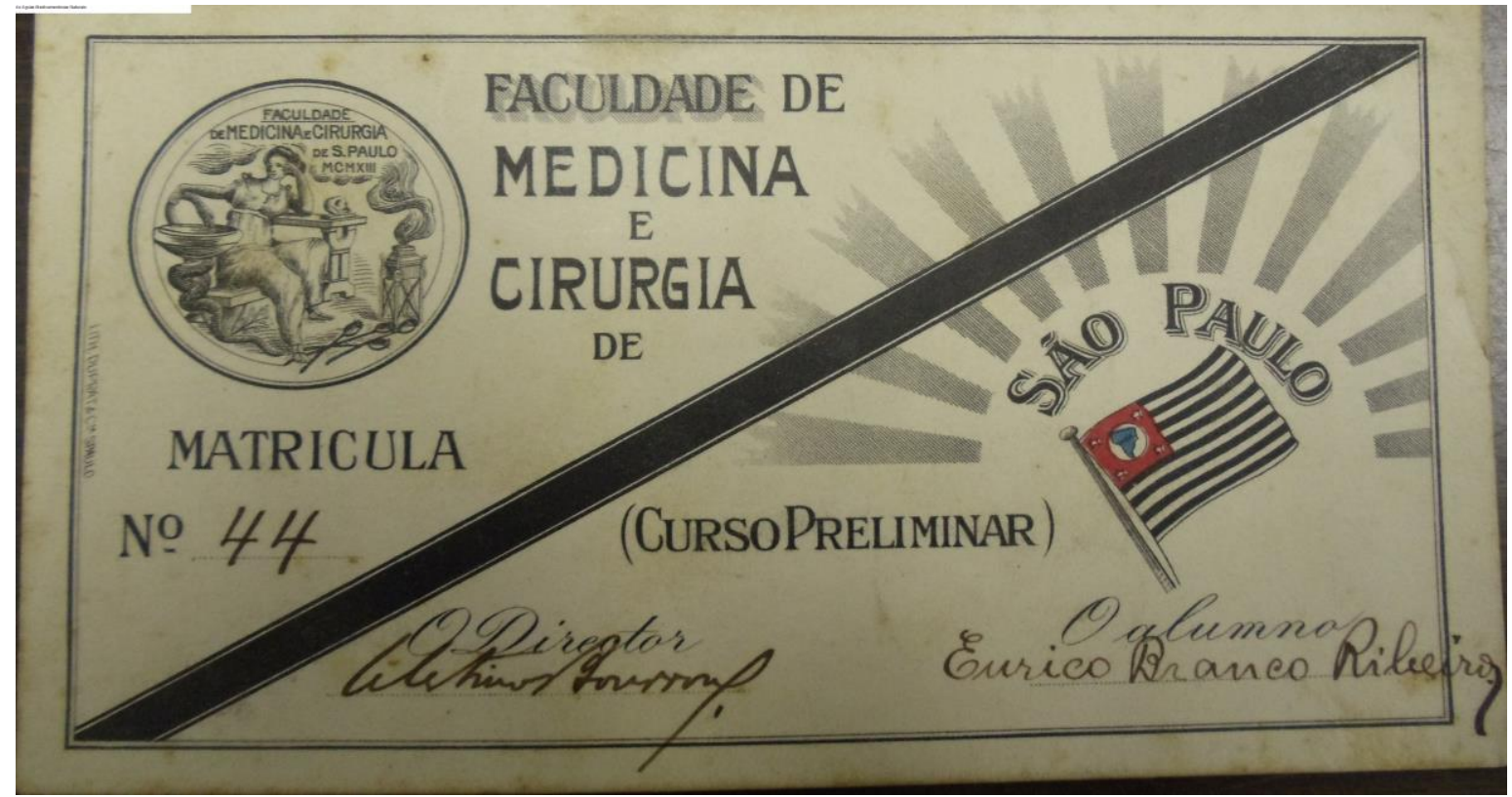

Fonte: Acervo do Museu Histórico da Faculdade de Medicina da USP - São Paulo/SP 